\title{
Quistes parauretrales femeninos. Experiencia de 4 casos
}

\author{
V. Menéndez López*, E. de Nova Sánchez**, C. Carro Rubias**, L. de Paz Cruz**, F. García López** \\ *Servicio y Cátedra de Urología. Hospital del Mar. UAB. Barcelona. \\ **Servicio de Urología. Hospital General Universitario de Elche. Alicante.
}

Actas Urol Esp 2006; 30 (1): 83-84

\section{RESUMEN}

QUISTES PARAURETRALES FEMENINOS. EXPERIENCIA DE 4 CASOS

Los quistes parauretrales son una patología poco frecuente. Presentamos 4 casos que fueron diagnosticados y tratados en nuestro hospital durante los últimos 10 años.

Palabras clave: Quiste parauretral. Diagnóstico. Tratamiento. Pronóstico.

\section{ABSTRACT}

FEMALE PARAURETHRAL CYSTS. EXPERIENCE OF 4 CASES

Parauthreal cysts are an uncommon pathology. We present 4 cases diagnosed and treated in our hospital during the last 10 years.

Keywords: Paraurethral cyst. Diagnosis, Treatment. Outcome.

$\mathrm{L}$ os quistes parauretrales son una patología rara, se forman a partir de restos embrionarios o de la obstrucción crónica de las glándulas parauretrales. El diagnóstico es clínico y se recomiendan estudios radiológicos para demostrar la ausencia de comunicación con la uretra o la asociación a otras patologías.

\section{CASOS CLÍNICOS}

Desde 1994 hasta 2004 fueron atendidas en el Hospital General Universitario de Elche 4 mujeres (edad media: 34 años; rango: 21-53 años) por quiste parauretral, tres en el servicio de urología y otra en el de ginecología. Todas las pacientes consultaron por la presencia de una tumoración adyacente al meato uretral. Dicha tumoración presentaba un diámetro que oscilaba entre 2 y $3 \mathrm{~cm}$ y con una evolución de entre 3 y 12 meses (uno de los quistes de una paciente puede observarse en la Figura 1). Únicamente una de las cuatro pacientes era nulipara. Ninguna refirió infecciones de orina, ni clínica miccional de ningún tipo. Las tumoraciones eran de consistencia elástica, y no se observaba salida de líquido por uretra tras exprimir las mismas. A todas las pacientes se les realizó cultivo de orina, ecografía y uretroscopia que resultaron normales.

Los tratamientos fueron: punción en tres de los casos, no siendo efectiva en dos de ellos pues el quiste volvió a reaparecer a los pocos meses, exéresis en un caso y marsupialización en dos. El líquido drenado en todos los casos tenía una apariencia viscosa, lechosa y de color entre amarillento y marrón. El cultivo del líquido drenado fue negativo.

La pared del quiste estaba compuesta por epitelio transicional en dos casos, y escamoso, en otro. De una paciente, a la que se realizó una punción simple, no disponemos de informe histológico.

\section{DISCUSIÓN}

Los quistes parauretrales son poco frecuentes. Pueden ser congénitos o adquiridos y sus manifestaciones clínicas pueden ser variables, como dolor, disuria, dispareunia, secreción vaginal o alteraciones miccionales. Sin embargo, lo más habitual es que sean asintomáticos ${ }^{1}$. No parece que exista un mayor predominio en ningún grupo de edad ${ }^{2}$, incluso se ha llegado a diagnosticar en neonatos ${ }^{3}$. 


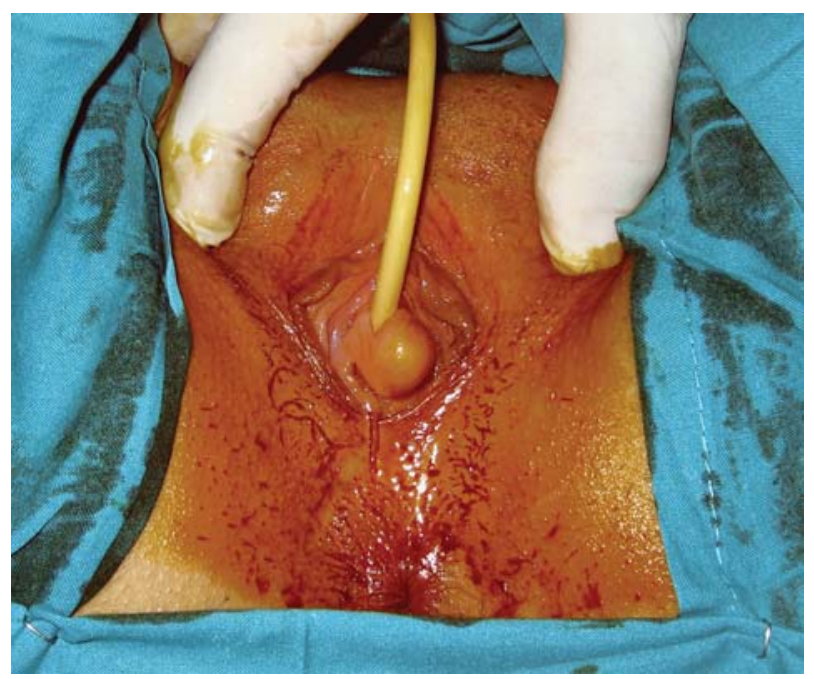

FIGURA 1. Quiste parauretral adyacente a la uretra.

Las glándulas parauretrales y los conductos de las mismas que desembocan en la uretra se consideran como homólogos rudimentarios de la próstata. Las glándulas de Skene son un tipo de glándulas parauretrales que secretan un material mucoide durante las relaciones sexuales para lubricar la uretra durante el coito.

Estas estructuras, junto a la uretra derivan en parte del seno urogenital. La migración del tejido urotelial hacia una zona adyacente puede ser la causa de la aparición de estos quistes, aunque también pueden ser causados por la inflamación y obstrucción de estas glándulas ${ }^{4}$.

El diagnóstico diferencial debe realizarse con ureteroceles ectópicos prolapsados, quistes de los conductos de Gartner, quistes de remanentes mü- llerianos, quistes de inclusión de la pared vaginal, neoplasias uretrales o vaginales, prolapso uretral y divertículos uretrales.

El sedimento urinario, la ecografía abdominal y la cistouretroscopia parecen ser las únicas pruebas necesarias para su correcto diagnósti$\mathrm{co}^{2}$, aunque algunos autores recomiendan la realización de una cistouretrografia ${ }^{5}$.

Debido a que la punción simple del quiste no suele ser suficiente para resolver el cuadro, se recomienda como tratamiento definitivo la marsupialización $^{2}$ o la exéresis del quiste ${ }^{5}$, habiéndose observado resultados similares.

\section{REFERENCIAS}

1. Stovall TG, Muram D, Long DM. Paraurethral cyst as an unusual cause of acute urinary retention. A case report. J Reprod Med 1989;34(6):423-425.

2. Sharifi-Aghdas F, Ghaderian N. Female paraurethral cysts: experience of 25 cases. BJU Int 2004;93(3):353-356.

3. Blaivas JG, Pais VM, Retik AB. Paraurethral cysts in female neonate. Urology 1976;7(5):504-507.

4. Kimbrough HM Jr, Vaughan ED Jr. Skene's duct cyst in a newborn: case report and review of the literature. J Urol 1977;117(3):387-388.

5. Deppisch LM. Cysts of the vagina: Classification and clinical correlations. Obstet Gynecol 1975;45(6):632-637.

Dra. V. Menéndez López

Servicio y Cátedra de Urología.

Hospital del Mar

Passeig Marítim, 25-29

08003 Barcelona

e-mail:violetamenendez@wanadoo.es

(Trabajo recibido el 8 de marzo 2005) 